\title{
Gender Interactions on Cutthroat Kitchen
}

\author{
Manya Kodali ${ }^{1}$ and Shannon Roos ${ }^{1}$ \\ ${ }^{1}$ Hampton High School, Allison Park, PA, USA
}

\section{ABSTRACT}

Traditional media has portrayed both genders in a biased manner, displaying differences in roles and personalities; this biased portrayal has a variety of impacts on people's lives and careers. The aim of this paper is to analyze interactions between each gender on the show Cutthroat Kitchen through a content analysis to discover whether or not gender impacts interaction types and frequencies. Ultimately, this paper has concluded that gender does affect interactions on the show due to the differing frequencies for various types of interactions such as insults and threats. Furthermore, the frequency of each gender initiating interactions differs along with the connotation of said interactions. These findings of this study have implications on the field of social psychology and the casting of reality T.V. shows, especially food-based ones.

\section{Introduction}

High viewership and ratings are central to the success of television shows; public scandal has the potential to severely damage both. TV shows that lose viewers and ratings due to controversies are often canceled. This has been seen in various shows such as 19 Kids and Counting, Buckwild, Ev and Ocho, and Rosanne (Singh 2018). In recent years, controversies within the media and entertainment industry have flooded the American news cycle. Thus, Food Network producers and directors have a clear interest in ensuring that the shows they are creating are as free from gender bias as possible to help guarantee the success of both the shows and the overall channel. However, producers are not the only ones that have an interest; contestants of these types of shows are also affected by bias because it affects their likelihood of winning and gaining the rewards or prizes from televised competitions. After considering this information, the researcher formed their guiding question: How much does gender impact competitors' interactions with one another on Cutthroat Kitchen?

\section{Literature Review}

\section{Key Definitions}

According to the Oxford Dictionary, reality T.V. is any show that is "based on real people (not actors) in real situations, presented as entertainment" (Reality-tv). Cutthroat Kitchen contestants are chefs, not actors, and the show is designed to amuse viewers rather than provide actual recipes or instruction, making it a reality show. It is also crucial to understand how Cutthroat Kitchen works and the premises of the show. Cutthroat Kitchen is a cooking competition on Food Network TV. The premise is quite simple: 4 chefs compete to make the best dish in an allotted amount of time, and whoever has the worst dish is eliminated. However, the host Alton Brown has created some unique challenges. Each chef starts with $\$ 25,000$ which they use to bid on "sabotages" before and during each round of cooking. If a chef wins a round of bidding, they get to give the "sabotage" to one of their fellow competitors; in turn, the sabotages make it harder for competitors to do well and make it into the next round. However, the contestants need to watch how much they spend because the winners only take home what they have left of the $\$ 25,000$. 


\section{History of Gender Bias}

During the 1900s, there was a clear gender bias in various forms of media. According to Kevin Smith, professor and chair of the political science department at the University of Nebraska-Lincoln, newspapers had systematic genderbased coverage of politicians that tended to disadvantage female candidates in the 1990s (Smith 1997). In advertisements, women were portrayed as housewives while men were shown as being successful and powerful (Furnham \& Mak 1999; Gilly 1988). Furthermore, over 50\% of prime-time television characters were male during the 1970 s (Bretl \& Cantor 1988). These studies, among others, exhibit the biased presentation of women in America's media throughout history. Unfair reporting and unequal screen time perpetuated gender perceptions and stereotypes of the 1990s, which in turn harmed women's opportunities. Many of these stereotypes that exist in today's media found their way into pop culture and the public eye through the media during the twentieth century. The 1990s were also the time in which Food Network rose to fame and was found in the majority of households (Gagliardi 2014). Due to its prevalence across all forms of media during this time period, bias was likely prevalent in Food Network during its rise to main-stream popularity.

\section{The Portrayal of Gender in Media}

Media has always affected people's lives and opinions. However, in the modern era, where technology is a constant presence, the media has a greater sphere of influence and a more severe impact on culture than ever before. Thus, it becomes important to analyze how each gender is portrayed in media and how these portrayals can impact people. Fewer females than males are shown across all media forms (Collins 2011). As a result, people who interact with media in any form are subjected to a skewed image of the scenarios being presented to them. Not only are women given fewer roles, but these limited roles are sexualized far more often than similar roles given to male counterparts, further skewing images portrayed in media. According to a study performed by L. Monique Ward, women are disproportionately objectified in prime-time programs (Ward 2003). This overly sexualized portrayal of girls in the media contributes to sexual harassment and harms girls' body image, confidence, and sense of identity (Report 2010). Not only does the over-sexualization of girls in media continue to distort perceptions, it affects the lives and health of women. So, the issue of media sexualization and overall media bias has extensive effects on society beyond the direct effect on women and Hollywood. In fact, the sexualization of women by others has been found to have a negative impact on women's professional careers (Glick, Larsen, Johnson, \& Branstiter 2005). Clearly, biased media has significant impacts on women's lives and careers. Female characters are also more likely to play roles in which they are more focused on their personal lives, while male characters are shown to focus on furthering their careers and becoming successful ( Lauzen 2017; Lauzen, Dozier, \& Horan 2008); this further harms women's self-image and once again has negative implications for their future careers.

While many may believe that media exists only as a form of entertainment with no real-life effects, a study performed by eleven professors in various fields of medicine supports the hypothesis that the internet and media influences and can even change people's brains and cognition (Firth et al. 2019), which supports the fact that gender biases in media have powerful repercussions on the careers of women and men. It becomes increasingly clear that media bias is prevalent today and has long-lasting impacts on women's health and livelihoods. These impacts extend to men as well, seeing as the media has been shown to directly alter the human brain and cognitive patterns.

\section{Differences in Competition due to Gender}

Seeing as Cutthroat Kitchen is a competition-based reality show and the fact that this paper specifically focuses on the interactions between competitors, it is necessary to consider past research on the relationship between gender and competition. A group of economics professors in various universities found that in patrilineal societies, girls 
begin to compete less when they reach puberty, but in matrilineal societies, girls continue to compete as they did before (Andersen, Ertac, Gneezy, List, and Maximiano 2013). This phenomenon indicates the idea that differing societal norms and cultures results in varying levels of ambition/competitiveness - meaning that differing levels of competitiveness may be a learned trait rather than an innate trait. Females are less likely to enter competitions than their equally-qualified male counterparts (Niederle \& Vesterlund 2011); this difference in willingness to compete could be due to a difference in confidence between each gender seeing as confidence has been linked to a greater interest in taking part in competitive activities (Ehrlinger \& Dunning 2003). Furthermore, females and males tend to prefer different types of competitions. Men tend to prefer to take part in tournament-style competitions in which a group of people competes and only the person who wins gains a reward, while women generally prefer noncompetitive piece-rate schemes in which they are rewarded consistently for each unit of output (Niederle \& Vesterlund 2011). This further supports the idea that males are more likely to participate in competitions simply due to preferences. Confidence strongly correlates to people's estimates of their own performance but does not predict their actual performance in competitive scenarios (Ehrlinger \& Dunning 2003). Therefore, it becomes clear that confidence likely plays a pivotal role in the participation of competitive activities, like Cutthroat Kitchen, but does not play a role in the actual results of said competitions. Women also tend to be more risk-averse than males; overall, women tend to be far more cautious than men both in laboratory experiments and in real-world scenarios (Eckel \& Grossman 2008). Competitions are inherently risky because not everyone wins,so the results of these studies may be another explanation for why fewer women take part in competitions.

\section{Assumptions}

By analyzing past studies investigating the relationship between gender and competition and the portrayal of gender in media, some conclusions are drawn. Firstly, women are often negatively portrayed through the use of disproportionate sexualization (Ward 2003), harming females' self-esteem along with their future ability to get a job (Report 2010). Next, women tend to be far less likely to take part in competitions even when qualified (Niederle \& Vesterlund 2011). This phenomenon has a few potential causes: a lack of confidence (Ehrlinger \& Dunning 2003) and levels of risk aversion (Eckel \& Grossman 2008). These ideas can be applied to new research topics. While competition has been studied extensively, a gap remains in the comprehensive study of competition within reality-based television shows and in the study of perceptions of fellow competitors. This paper aims to begin to fill that gap by investigating how gender influences perception during a food competition, leading the researcher to the question: How much does gender affect competitors' interactions with one another on Cutthroat Kitchen?

\section{Method}

\section{Introduction}

In order to find an answer to the research question, a content analysis was applied to a random sampling of Cutthroat Kitchen episodes. This method was applied to achieve an analysis of the themes and messages conveyed by contestants. IRB approval was given before the research process started.

The researcher considered a variety of methods before beginning data collection. A case study was first considered in the hopes of gaining an in-depth knowledge of one group of contestants and their perceptions of one another on Cutthroat Kitchen. However, this method was rejected due to the fact that the researcher would have only watched one episode of Cutthroat Kitchen, the small scale would have given the researcher a very narrow view of Cutthroat Kitchen interactions.

An ethnographic study was also initially considered, seeing as it would give the researcher a unique immersive experience showcasing how the set's competitive atmosphere affects contestent interactions and perceptions. 
This method was overall infeasible due to the fact that the researcher could not visit the set and observe contestants before, during, and/or after filming.

A content analysis was ultimately chosen to allow the researcher to collect data on contestant interactions through the viewing of episodes. This method allows the researcher to gain an understanding of gender's effect on interactions through a thematic analysis without requiring them to meet with contestants. Analyzing multiple episodes also gives a broader perspective through the experiences of multiple groups of contestants.

Connotation was determined to provide a more in-depth look into the emotions/opinions conveyed in each statement. This part of the analysis applied an approach created by Wilson, Wiebe, and Hoffman to perform phraselevel sentiment analysis. Wilson, Wiebe, and Hoffman are members of the Intelligent Systems Program and Department of Computer Science at the University of Pittsburgh. They define sentiment analysis as "the task of identifying positive and negative opinions, emotions, and evaluations" (Wilson, Wiebe, \& Hoffmann 2005). This factor of the overall analysis allowed the researcher to gauge the attitudes conveyed by contestants during their interactions.

\section{Episode Selection}

The researcher had access to seasons 4-10 of the show through a Hulu account. All episodes in seasons 4, 6, 7, 8, 9, and 10 were available; the researcher only had access to episodes $1,2,3,5,7,9,12$, and 13 of season 5 . A random sampling of episodes was necessary to obtain accurate results that can be generalized to the greatest number of $\mathrm{Cut}$ throat Kitchen episodes. To achieve this, abnormal episodes were first removed. These episodes were ones in which all the contestants are one gender, in which the contestants include partners/groups, or episodes with more/less than the normal number of contestants - four. These were removed due to the fact that they may have different gender distributions or different interactions than the average episode. In total, 8 episodes were removed for a variety of reasons.

Table 1. Episode Selection

\begin{tabular}{|c|c|c|c|c|}
\hline Season & $\begin{array}{c}\text { Original } \\
\text { Number of } \\
\text { Episodes }\end{array}$ & $\begin{array}{c}\text { Episodes } \\
\text { Removed }\end{array}$ & Reason for Removal & $\begin{array}{c}\text { Number of Epi- } \\
\text { sodes Remain- } \\
\text { ing }\end{array}$ \\
\hline 4 & 13 & None & N/A & 13 \\
\hline 5 & 8 & None & Episode 3 & $\begin{array}{c}\text { Episode 3 contained sets of twins competing } \\
\text { against each other. The lifelong sibling relation- } \\
\text { ships would have skewed perceptions and therefore } \\
\text { interactions. }\end{array}$ \\
\hline 6 & 13 & $\begin{array}{c}\text { Episode 11 } \\
\text { Episode 13 }\end{array}$ & $\begin{array}{c}\text { Both episodes had 4 male contestants, so the gen- } \\
\text { der distributions were abnormal. }\end{array}$ \\
\hline 7 & 13 & None & $\begin{array}{c}\text { N/A } \\
\text { Episode 4 } \\
14-17\end{array}$ & $\begin{array}{c}\text { Episode 4 had 4 female contestants, so the gender } \\
\text { distributions were abnormal. }\end{array}$ \\
\hline 9 & 18 & r & 13 \\
\hline
\end{tabular}




\begin{tabular}{|l|c|c|c|c|}
\hline & & & $\begin{array}{c}\text { Episodes 14-17 each had only three contestants, so } \\
\text { the gender distributions were abnormal. }\end{array}$ & 13 \\
\hline 10 & 13 & None & N/A & 13 \\
\hline
\end{tabular}

After removing all abnormal episodes, seventy episodes remained. These were numbered in numerical order starting at Season 4 Episode 1, skipping each removed episode, and continuing until Season 10 Episode 13. Then, using a random number generator, ten numbers were selected. The episodes that correspond to each number were watched and coded by the researcher.

Table 2. Episodes Coded

\begin{tabular}{|c|c|}
\hline Random Number Selected & Episodes that Correlate to Randomly Selected Numbers \\
\hline 13 & Season 4, Episode 13 \\
\hline 68 & Season 9, Episode 2 \\
\hline 30 & Season 6, Episode 10 \\
\hline 16 & Season 5, Episode 3 \\
\hline 20 & Season 5, Episode 12 \\
\hline 27 & Season 6, Episode 7 \\
\hline 46 & Season 8, Episode 2 \\
\hline 21 & Season 5, Episode 13 \\
\hline 61 & Season 9, Episode 5 \\
\hline 57 & Season 8, Episode 13 \\
\hline
\end{tabular}

\section{Data Collection}

While watching each episode, every verbal interaction between contestants was recorded. This includes direct statements to one another before/during cooking, statements about fellow contestants during private confessional interviews, and voiceovers about fellow contestants. Obvious tones with which the statements were said (ie. anger), clear body language, and distinct facial expressions (ie. eye rolling), if they occurred, while speaking or while reacting to something said about another contestant, were also recorded. If no distinct body language, tone, or facial expressions were made during an interaction, the corresponding spot on the spreadsheet was left blank (this was to prevent researcher bias through assumption of body language, tone, and/or expressions). 


\section{Coding Scheme}

Keyword(s) were first selected from each statement. Next, the polarity of each statement was recorded to be positive, negative, both, or neutral. The polarity describes the overall connotation or emotion conveyed through the statement along with its intensity. The intensity - low, medium, high, or extreme - was also recorded to describe the strength of the emotion conveyed. This general framework was adapted from a 2005 approach created by Wilson, Wiebe, and Hoffman to perform phrase-level sentiment analysis.

Descriptor statements (themes) were assigned to each statement; the themes were chosen by considering what the keyword(s) communicated. After the theme was assigned to each statement, the themes were ordered by increasing frequency of occurrence. The most frequent themes serve as the overarching themes found in Cutthroat Kitchen. Each episode was coded twice to minimize coder error and bias.

\section{Findings \& Analysis}

Results

Table 3. Themes By Frequency

\begin{tabular}{|c|c|c|c|}
\hline Theme & $\begin{array}{l}\text { Number of Occur- } \\
\text { rences }\end{array}$ & $\begin{array}{l}\text { Percent Occur- } \\
\text { rence }\end{array}$ & $\begin{array}{l}\text { Connotation (Nega- } \\
\text { tive/Positive) }\end{array}$ \\
\hline Insults & 113 & $32.01 \%$ & Negative \\
\hline Concern for Others & 46 & $13.03 \%$ & Positive \\
\hline Jokes & 43 & $12.18 \%$ & Positive \\
\hline Confidence & 32 & $9.06 \%$ & Positive \\
\hline Threatening Others & 30 & $8.50 \%$ & Negative \\
\hline Nicknames & 27 & $7.65 \%$ & Negative \& Positive \\
\hline Annoyance Over Being Sabotaged & 24 & $6.80 \%$ & Negative \\
\hline Kindness & 9 & $2.50 \%$ & Positive \\
\hline Innuendo & 7 & $2.00 \%$ & Negative \\
\hline Apologizing & 7 & $2.00 \%$ & Positive \\
\hline Annoyance Over Bid Prices & 6 & $1.70 \%$ & Negative \\
\hline $\begin{array}{c}\text { Enjoying Another Competitor Suffering } \\
\text { Through a Sabotage }\end{array}$ & 5 & $1.42 \%$ & Negative \\
\hline Feeling Nervous & 4 & $1.13 \%$ & Negative \\
\hline
\end{tabular}


Among all theme occurrences, insults of some kind were the most common at $32.01 \%$ of all interactions. In total, negative themes account for $53.56 \%$ of the total interactions and positive interactions make up $38.79 \%$ of total interactions; nicknames were excluded from this count seeing as they can be used in either context.

Table 4. Theme Occurrences by Gender

\begin{tabular}{|c|c|c|c|c|c|}
\hline Theme & $\begin{array}{c}\text { Theme } \\
\text { Total }\end{array}$ & $\begin{array}{c}\text { Male-Male } \\
\text { Total }\end{array}$ & $\begin{array}{c}\text { Female-Female } \\
\text { Total }\end{array}$ & $\begin{array}{c}\text { Male-Female } \\
\text { Total }\end{array}$ & $\begin{array}{c}\text { Female-Male } \\
\text { Total }\end{array}$ \\
\hline Insults & 113 & 53 & 10 & 22 & 28 \\
\hline Concern for Others & 46 & 24 & 0 & 9 & 13 \\
\hline Jokes & 43 & 22 & 1 & 7 & 13 \\
\hline Confidence & 32 & 14 & 3 & 5 & 10 \\
\hline Threatening Others & 29 & 5 & 2 & 10 & 12 \\
\hline Nicknames & 27 & 16 & 1 & 2 & 8 \\
\hline Annoyance Over Being Sabotaged & 24 & 13 & 4 & 1 & 6 \\
\hline Kindness & 9 & 6 & 2 & 0 & 1 \\
\hline Innuendo & 7 & 5 & 0 & 2 & 0 \\
\hline Apologizing & 7 & 1 & 0 & 2 & 4 \\
\hline $\begin{array}{c}\text { Enjoying Another Competitor Suffering } \\
\text { Through a Sabotage }\end{array}$ & 6 & 6 & 0 & 0 & 0 \\
\hline Annoyance Over Bid Prices & 6 & 0 & 1 & 1 & 4 \\
\hline Feeling Nervous & 4 & 1 & 1 & 0 & 2 \\
\hline Total Occurrences & 353 & 166 & 25 & 61 & 101 \\
\hline
\end{tabular}

Table 4 shows the total interactions within and between each gender for each theme. Several significant thematic proportion differences emerged. Male-male interactions occurred $47.0 \%$ of the time, and male-female interactions occurred $17.3 \%$ of the time. So, males-initiated interactions a vast majority of the time at a total of $64.3 \%$ of the time. Furthermore, females interacted with other females only $7.1 \%$ of the time, while they chose to initiate interactions with males $28.6 \%$ of the time. Male-male interactions were the majority interaction type in every theme except for "Threatening Others", where female-male interactions are the majority. 
Table 5. Negative Themes and Gender

\begin{tabular}{|c|c|c|}
\hline $\begin{array}{c}\text { Interaction } \\
\text { by Gender }\end{array}$ & $\begin{array}{c}\text { Number of } \\
\text { Occurrences }\end{array}$ & $\begin{array}{c}\text { Percent Oc- } \\
\text { currences }\end{array}$ \\
\hline Male-Male & 82 & $43.62 \%$ \\
\hline $\begin{array}{c}\text { Female- } \\
\text { Female }\end{array}$ & 18 & $9.57 \%$ \\
\hline Male-Female & 36 & $19.15 \%$ \\
\hline Female-Male & 52 & $27.66 \%$ \\
\hline Total & 188 & $100 \%$ \\
\hline
\end{tabular}

Table 6. Positive Themes and Gender

\begin{tabular}{|r|c|c|}
\hline $\begin{array}{c}\text { Interaction } \\
\text { by Gender }\end{array}$ & $\begin{array}{c}\text { Number of } \\
\text { Occurrences }\end{array}$ & $\begin{array}{c}\text { Percent Oc- } \\
\text { currences }\end{array}$ \\
\hline Male-Male & 67 & $48.91 \%$ \\
\hline $\begin{array}{c}\text { Female- } \\
\text { Female }\end{array}$ & 6 & $4.38 \%$ \\
\hline Male-Female & 23 & $16.79 \%$ \\
\hline Female-Male & 41 & $29.93 \%$ \\
\hline Total & 137 & $100 \%$ \\
\hline
\end{tabular}

Note: Nicknames were removed from Charts 3 and 4 due to the fact that the connotation of nicknames is heavily dependent on tone, context, and personality and is therefore neither positive or negative.

Negative interactions were overall more prevalent than positive interactions and comprised $53.54 \%$ of all interactions. Male-male interactions were the majority interaction type for both positive and negative interactions at $48.91 \%$ and $43.62 \%$ of each respectively. Female-female interactions were the least likely to be positive in nature with only $4.38 \%$ of positive interactions being made in this category.

Table 7. Episodes and Gender Distributions

\begin{tabular}{|r|c|c|}
\hline Season, Episode & Number of Male Contestants & Number of Female Contestants \\
\hline Season 8, Episode 13 & 2 & 2 \\
\hline Season 9, Episode 5 & 3 & 1 \\
\hline Season 5, Episode 13 & 3 & 1 \\
\hline Season 8, Episode 2 & 3 & 1 \\
\hline Season 5, Episode 3 & 3 & 1 \\
\hline Season 4, Episode 13 & 3 & 1 \\
\hline Season 5, Episode 12 & 3 & 1 \\
\hline
\end{tabular}




\section{Analysis}

Elizabeth Cashdan, a professor of anthropology at Cambridge University, found that there was "no significant difference in verbal aggression between the two genders (defined as 'put-downs, barbed humour, sarcasm, being argumentative, etc.')" (Cashdan 2001). However, in Cutthroat Kitchen, themes such as insults and enjoying others suffering were most prevalent in the male-male category. Insults and the enjoyment of others suffering clearly fit within Cashdan's description of verbal aggression and are thus comparable to her research. Male initiated insults (malemale and male-female) happened a total of 75 times, accounting for $66.37 \%$ of all insults, while female initiated insults (female-female and female-male) happened only 38 times which was $33.63 \%$ of all insults. The theme "Enjoying Another Competitor Suffering Through a Sabotage" occurred 6 times; all six times were male initiated. So, it becomes clear that in Cutthroat Kitchen, verbal aggression is far more frequently initiated by males than by females which directly contradicts Cashdan's findings.

Regarding general frequencies of interactions between/within each gender, Cashdan found that "Both the women and the men. . . were far more likely to compete against members of their own sex, but this was particularly the case for men" (Cashdan 2001). The researcher's results somewhat mimic Cashdan's findings; the researcher used interaction frequencies as a measure to quantify the contestants' willingness to compete with one another. It is true that males tend to initiate interactions with other men more often than they initiated interactions with females, seeing as male-male interactions occur 166 times while male-female interactions occur 61 times. However, females tended to initiate interactions with males far more than with fellow females. Female-female interactions only occured 25 times, but females-initiated interactions with men 101 times.

The theme of kindness was made up of three subcategories: compliments, supporting another competitor, and offering help to another competitor. The researcher found only 9 instances of kindness with 6 being male-male interactions, 2 being female-female interactions, and 1 being a female-male interaction; so, men tend to be kinder. A group of psychologists found that "men become more altruistic [and less selfishly when their group is competing]" (Vugt, Cremere, \& Janssen 2007). Similarly, to this past research, the researcher found that kindness was seen more often initiated by male competitors. The subcategories of the researcher's theme "Kindness" fit within the larger umbrella term "altruistic". Van Vugt's study focused on competition between groups rather than competition between individuals as in Cutthroat Kitchen, however there are still similarities regarding the psychology of competitions. A study performed by a group of psychology professors and published in PLOS ONE, a peer reviewed journal of science, found that "when two individuals who are from different groups are competing with each other, they may make self-interested decisions" (Liu, Lin, \& Xin 2014). Even when part of a group, the individual members still act towards their own self-interest during competition - indicating a strong psychological link between individual competition and group competition exists, allowing conclusions from Vugt's group study to be applied at a basic level to the researcher's findings regarding competition between individuals on Cutthroat Kitchen.

On a broader scale, regarding media as a whole, Cutthroat Kitchen conforms to general trends seen in past studies. According to Rebecca Collins, a senior behavioral scientist, fewer females than males are shown across all media forms (Collins 2011). This was seen in 7 of the episodes which all had only 1 female contestant and 3 male contestants. The remaining 3 episodes had 2 females and 2 males with 0 episodes having a larger number of females. This data can be viewed in Table 7. Episodes and Gender Distributions.

So, in the sample studied, $32.5 \%$ of contestants were female and $67.5 \%$ of contestants were male. These values confirm Collins' conclusion as being true in the T.V. show Cutthroat Kitchen. The researcher's findings further relate to Niedrele and Vesturland's study which found that men on average take part in tournament-style competitions where a group of people competes and only the person who wins gains a reward more often than women do (Niederle \& Vesterlund 2011); Cutthroat Kitchen is a tournament style competition because 4 people compete and 
the last one standing gets the reward of their remaining money, and $67.5 \%$ of the show's contestants are male. It is evident that in terms of males being more prevalent than females, Cutthroat Kitchen gender distributions match Collins and Niederle's findings.

\section{Discussion}

\section{Limitations}

This study had a few limitations. Firstly, only one coder was used for analysis; the coder may have misinterpreted data leading to flawed themes. The researcher attempted to mitigate this possibility by coding the data two times to ensure the same themes with the same frequencies were found. Secondly, some interaction types, such as nicknames, are heavily reliant on the personality of whoever is speaking, the tone used, and the larger relationship of two contestants. So, some interaction frequencies may be more dependent on specific personalities rather than applicable to Cutthroat Kitchen as a whole. The research was also confined by the nature of TV shows; all TV shows go through rounds of editing, and reality TV especially can be heavily edited to influence viewer's opinions of the contestants. Thus, there may have been interactions removed or edited in ways that affected the thematic analysis. However, because this study aimed to fill a gap specific to research on reality TV shows, the results still stand within the small scope. Additionally, there is little to no past research regarding interactions within competition TV shows, especially when gender is considered. So, this study had little prior data that could be related or used to corroborate the results.

\section{Conclusions}

The question the researcher aimed to answer is: to what extent does gender affect competitor's interactions with one another on Cutthroat Kitchen? There was little to no past research on gender interactions in a competition scenario, so this research had little former results to corroborate the validity. Regarding the past research that does exist, some of it, such as Cashdan's paper, contradicted the researcher's findings. Other papers like Niederele and Vesterlund and Vugt et al. verified the researcher's results. It was found that in Cutthroat Kitchen, gender played a role in interaction frequencies with males initiating interactions far more frequently than females. Verbal aggression and kindness were both found to be male-initiated far more frequently than female-initiated. Overall, males were far more prevalent than female contestants on the show, supporting trends found in all media sources by Rebecca Collins and relating to Niedrele and Vesturland's paper regarding competition types.

Ultimately there were a variety of interactions affected by gender. These results affect the field of social psychology because the field studies interactions, which this paper focused on. Furthermore, producers of reality TV shows may consult these findings when considering the casting of contestants of each gender on shows in order to manufacture interactions they want on their show or in an attempt to make gender portrayals more equal.

The results of this study prompt further inquiry into the relationships between gender and interaction during competition TV shows. Future researchers could replicate this study on many other Food Network competition shows to see if these interaction trends hold true for other food-based shows. Gaining access to copies of the film pre-editing would be another route for future research; this would allow contestant interactions to be viewed without the bias of reality T.V. editing. To address the limitation regarding personality, future studies could also include personality types as a variable to help find the extent to which gender, rather than personality, affects interactions. These would all broaden the understanding of the relationship between gender and interaction in a competitive setting.

\section{Acknowledgements}


I'd like to thank my teacher, Mrs. Roos, for supporting and guiding me throughout the process.

\section{Bibliography}

Andersen, S., Ertac, S., Gneezy, U., List, J. A., \& Maximiano, S. (2013). Gender, Competitiveness, and Socialization at a Young Age: Evidence From a Matrilineal and a Patriarchal Society. Review of Economics and Statistics, 95(4), 1438-1443. doi: 10.1162/rest_a_00312

Bretl, D. J., \& Cantor, J. (1988). The portrayal of men and women in U.S. television commercials: A recent content analysis and trends over 15 years. Retrieved November 5, 2019, from

https://link.springer.com/article/10.1007/BF00287963.

Cashdan, E. (2001). Are men more competitive than women? British Journal of Social Psychology, 37(213). Doi: 10.1111/j.2044-8309.1998.tb01166.x

Collins, R. L. (2011). Content Analysis of Gender Roles in Media: Where Are We Now and Where Should We Go? Sex Roles, 64(3-4), 290-298. doi: 10.1007/s11199-010-9929-5

Eckel, C. C., \& Grossman, P. J. (2008). Chapter 113 Men, Women and Risk Aversion: Experimental Evidence. Handbook of Experimental Economics Results, 1061-1073. doi: 10.1016/s1574-0722(07)00113-8

Ehrlinger, J., \& Dunning, D. (2003). How chronic self-views influence (and potentially mislead) estimates of performance. Journal of Personality \& Social Psychology, 84(1). doi: 10.1037//0022-3514.84.1.5

Firth, J. et al. (2019). The "online brain": how the Internet may be changing our cognition. World Psychiatry. doi: $10.1002 /$ wps. 20617

Furnham, A., Mak, T. Sex-Role Stereotyping in Television Commercials: A Review and Comparison of Fourteen Studies Done on Five Continents Over 25 Years. Sex Roles 41, 413-437 (1999). https://doi.org/10.1023/A:1018826900972

Gagliardi, N. (2014). Is The Food Network Still Relevant? Retrieved November 5, 2019, from https://www.forbes.com/sites/nancygagliardi/2014/11/17/is-the-food-network-still-relevant/\#568daaa63b5e.

Gilly, M. C. (1988). Sex Roles in Advertising: A Comparison of Television Advertisements in Australia, Mexico, and the United States. Journal of Marketing, 52(2), 75. doi: 10.2307/1251266

Glick, P., Larsen, S., Johnson, C., \& Branstiter, H. (2005). Evaluations of sexy women in low- and high-status jobs. Psychology of Women Quarterly, 29, 389-395. doi:10.1111/j.1471-6402.2005.00238.x

Lauzen., M. M., Dozier, D., \& Horan, N. (2008). Constructing Gender Stereotypes Through Social Roles in PrimeTime Television. Journal of Broadcasting \& Electronic Media. doi: 10.1080/08838150801991971

Lauzen, M. M. (2017). Boxed In 2016-17: Women On Screen and Behind the Scenes in Television. Center for the Study of Women in Television and Film 16. Retrieved from https://womenintvfilm.sdsu.edu/wpcontent/uploads/2017/09/2016-17 Boxed In Report.pdf 
Liu, G., Lin, C., \& Xin, Z. (2014). The Effects of Within-and Between-Group Competitions on Trust and Trustworthiness among Acquaintances. PLoS One, 9(7). Doi: 10.1371/journal.pone.0103074

Niederle, M., \& Vesterlund, L. (2011). Gender and Competition. Annual Review of Economics. doi:10.1146/annurev-economics-111809-125122

Reality-tv noun - Definition, pictures, pronunciation and usage notes: Oxford Advanced Learner's Dictionary at OxfordLearnersDictionaries.com. (n.d.). Retrieved November 11, 2019, from https://www.oxfordlearnersdictionaries.com/us/definition/english/reality-tv.

Report of the APA Task Force on the Sexualization of Girls. (2010). PsycEXTRA Dataset. doi: 10.1037/e509462014-001

Singh, O. (2018). 15 TV shows that were canceled because of controversies. Retrieved November 11, 2019, from https://www.businessinsider.com/controversial-tv-shows-canceled-2018-5?amp;utm medium=referral\#paula-deensfood-network-empire-came-crashing-down-because-of-racial-slurs-12.

Smith, K. B. (1997). When Alls Fair: Signs of Parity in Media Coverage of Female Candidates. Political Communication, 14(1), 71-82. doi: 10.1080/105846097199542

Vugt, M. V., Cremere, D. D., \& Janssen, D. P. (2007). Gender Differences in Cooperation and Competition. Psychological Science, 18, 19-23. Doi: 10.1111/j.1467-9280.2007.01842.x

Ward, L. M. (2003). Understanding the role of entertainment media in the sexual socialization of American youth: A review of empirical research. Developmental Review, 23, 347-388

Wilson, T., Wiebe, J., \& Hoffmann, P. (2005). Recognizing contextual polarity in phrase-level sentiment analysis. Proceedings of the Conference on Human Language Technology and Empirical Methods in Natural Language Processing - HLT 05. doi: 10.3115/1220575.1220619 